\title{
KEARIFAN LOKAL LINGKUNGAN KOMUNIKASI REMBUG DESA DALAM MENJAGA KELESTARIAN HUTAN DI KESATUAN PEMANGKUAN HUTAN (KPH) BANYUMAS TIMUR
}

\author{
Ch. Herutomo \\ Fakultas Ilmu Sosial dan Ilmu Politik, Universitas Jenderal Soedirman \\ Email: christoherutomo@gmail.com
}

\begin{abstract}
ABSTRAK
Salah satu kearifan lokal lingkungan dalam menjaga kelestarian hutan adalah komunikasi rembug desa yang dimiliki oleh masyarakat hutan khususnya di Pulau Jawa. Dalam komunikasi rembug desa sebagai lembaga demokrasi masyarakat desa hutan masyarakat punya kebebasan berbicara dengan spontan, humor tanpa distorsi dan keputusan diambil melalui musyawarah dan mufakat. Kearifan lokal sebagai nilai sosial budaya masyarakat desa hutan diwariskan secara turun temurun itu dapat membina hubungan yang harmonis anatara masyarakat desa hutan dengan hutan. Hubungan yang harmonis itu ditunjukkan dengan prilakunya sebagai penjaga hutan, mereka sadar bahwa hutan merupakan bagian dari ekosistem. Mereka akan hidup nyaman bila hutan aman sebaliknya akan hidup sengsara bila hutan mengalami kerusakan.
\end{abstract}

Kata kunci : kearifan lokal, hutan lestari, rembug desa 


\section{PENDAHULUAN}

Dalam hubungannya dengan hutan masyarakat desa hutan mempunyai kearifan lokal yang salah satunya berupa komunikasi rembug desa yang diwariskan secara turun temurun dan sudah menjadi nilai budaya khususnya masyarakat desa hutan di pulau jawa. Kearifan lokal komuikasi rembug desa yang juga berkembang di wilayah Kesatuan Pemangkuan Hutan (KPH) Banyumas timur ini, isinya berbeda antara masyarakat desa hutan yang satu dengan yang lainnya sesuai dengan kondisi sosial budaya , bentuk ekosistem dan yang diwariskan secara turun temurun. Perbedaan juga disebabkan karena adanya tantangan hutan yang berbeda dan masyarakat desa hutan punya pengalamannya masing masing dalam memenuhi kebutuhannya, disamping itu kearifan lokal komunikasi rembug desa masyarakat desa hutan bersifat dinamis sesuasi tantangan yang berbeda dari waktu ke waktu. Dalam beradaptasi dengan lingkungan hutan masyarakat desa hutan dapat mengembangkan kearifan lokal komunikasi rembug desa berupa gagasan dan prilaku yang sesuai dengan nilai sosial budayanya untuk mengelola hutan. Melalui komunikasi rembug desa secara empiris sumber daya hutan akan lebih baik dan hal itu ditunjukan dengan, kebijakan dan tindakan masyarakat desa hutan yang lebih peduli dengan lingkungan hutan sehingga hutan bisa terjaga kelestariaannya.

Komunikasi rembug desa sebagai perwujudan nilai - nilai lokal positif yang dimiliki oleh masyarakat desa hutan di wilayah Kesatuan Pemangkuan Hutan ( KPH ) Banyumas Timur sebagai bentuk forum komunikasi kelompok yang terjadi sharing informasi, bebas berbicara tanpa distorsi, spontan, penuh humor dan keputusan diambil melalui musyawarah mufakat . Dalam komunikasi rembug desa ini mereka berbicara " ca -blaka " sebagai salah satu karakter masyarakat Banyumas. $\mathrm{Ca}$ - blaka artinya bicara apa adanya, terus terang, tanpa basa-basi dan blakblakan. Dalam mengungkapkan sesuatu termasuk mengkritik dan berbeda pendapat disampaikan dengan terbuka, humor sehingga tidak ada yang merasa sakit hati diantara mereka maka situasi 
komunikasinya tetap cair dan mengenakkan.

Membahas hutan lestari atau hutan berkelanjutan tidak dapat dipisahakan dari pembangunan berkelanjutan yang berwawasan lingkungan atau juga disebut "sustainable development" yang menggambarkan adanya saling ketergantungan antara pembangunan dan lingkungan termasuk hutan. Hutan sebagai salah satu bagian dari pembangunan berkelanjutan sudah tidak lagi hanya sekedar sebagai sumber pangan tetapi sebagai sumber pendapatan dan kegiatan ekonomi yang sangat menguntungkan. Kenyataan hutan telah menjadi sumber kegiatan ekonomi adalah adanya perambahan hutan atau perencekan hutan yang dilakukan oleh masyarakat sekitar hutan karena kemiskinan dan kerentanan sosial yang terjadi di masyarakat desa hutan.

Terjadinya perambahan atau perencekan tegakan hutan dan dalam skala besar pengalihan fungsi lahan hutan dan illegal loging telah memberikan kontribusi yang sangat besar terjadinya degradasi dan deforestasi hutan. Besarnya degradasi dan deforestasi hutan jelas berpengaruh besar terhadap kualitas dan daya dukung hutan terhadap lingkungan. Setelah krisis ekonomi tahun 1998 (Stevens, 2001) hutan di pulau Jawa kerusakannya makin parah, dalam tiga tahun setelah krisis ekonomi 1998 diperkirakan 350 ribu hehtar dalam pengelolaan Perum Perhutani dalam kondisi kritis, apalagi kalau dihitung kerugian dari aspek lingkungan seperti kuantitas dan kualitas air terganggunya habitat flora fauna dan makin terpinggirkannya masyarakat sekitar hutan.

Menurut catatan Kementerian Lingkungan Hidup Dan Kehutanan tahun 2017 sedikitnya 1,1 juta hektar atau sekitar $2 \%$ hutan di Indonesia menyusut tiap tahun tahunnya. Sekitar 130 juta hektar yang ada 1,3 juta hektar mengalami kerusakan. Sejak tahun 2010 sampai tahun 2015 Indonesia menempati urutan kedua tertinggi kehilangan luas hutannya yang mencapai 684.000 setiap tahunnya. Kerusakan hutan di Indonesia menurut Global Forest Watch meningkat pada tahun 2012 seluas 928.000 hehtar menurun tahun 2013, kemudian mengingkat kembali tahun 2014 seluas 796,500 hektar dan 
tahun 2015 seluas 735 hektar. Ancaman terbesar terhadap hutan adalah penebanagn liar, alih fungsi lahan, eksploitasi hutan dan perambahan.

Melihat degradasi dan deforestasi hutan yang mengkhawatirkan akan merusak daya dukung hutan yang dapat menurunkan fungsi ekologi dan ekonomi hutan. Kondisi demikian menjauhkan dari konsep hutan yang lesatari, dan telah menimbulkan inovasi kehutanan yang disebut dengan social forestry yaitu sebuah konsep pengelolaan hutan yang berbasis komunitas atau dikenal sebagai co-management. Konsep social forestry ini di Indonesia dikenal dengan konsep Pengelolaan Hutan Bersama Masyarakat (PHBM) yang merupakan forum kolaboratif antara masyarakat desa hutan (MDH), Kesatuan Pemangkuan Hutan, pemerintah dan stage holder.

Konsep social forestry yang di Indonesia di adopsi melalui Pengelolaan Hutan Bersama Masyarakat (PHBM) itu mulai dikembangkan pada era reformasi tahun 1998. Pada saat itu terjadi penjarahan hutan besar-besaran yang disebabkan oleh faktor kemiskinan akibat krisis moneter tahun 1998. PHBM yang salah satunyanya dikoordinir oleh Kesatuan Pemangkuan Hutan (KPH) Banyumas Wilayah Timur sebagai lembaga struktural kehutanan dibawah Perhutanai beserta para stakeholder seperti Lembaga Masyarakat Desa Hutan (LMDH), pemerintah. Dalam PHBM ini ada salah satu unsur yang disebut dengan Forum Komunikasi Pengelolaan Hutan Bersama Masyarakat (FK PHBM). Forum Komunikasi PHBM merupakan forum kolaborasi antara masyarakat desa hutan dengan para stakeholder yang dalam forum kolaborasi yang salah satunya kegiatannya dilakukan melalui forum komunikasi rembug desa yang dilakukan secara formal terjadwal maupun non formal.

\section{METODE PENELITIAN}

Metode penulisan ini menggunakan bentuk deskriftif kualitatif dengan menggunakan data primer maupun sekunder. Data primer diperoleh melalui observasi terhadap bagaimana proses komunikasi rembug desa pada forum 
KEARIFAN LOKAL LINGKUNGAN KOMUNIKASI REMBUG DESA DALAM MENJAGA

KELESTARIAN HUTAN DI KESATUAN PEMANGKUAN HUTAN (KPH) BANYUMAS TIMUR

komunikasi pengelolaan hutan

komunikasi interpersonal dan

bersama nasyarakat, sedangkan data

komunikasi kelompok. Menurut

sekunder diperoleh dari data statistik

dan dokumen dari Kesatuan

Pemangkuan Hutan (KPH)

Banyumas Wilayah Timur dan

Perhutani. Untuk mendapatkan data

yang valid penulis menggunakan

trianggulasi sumber yang dilakukan

dengan cara membandingkan data

hasil observasi dengan wawancara

dan wawancara dengan dokumen

yang berkaitan Untuk

menjawab permasalahan penulis

menggunakan analisa model

interaktif melalui proses

pengumpulan data, reduksi dan

verifikasi.

\section{HASIL DAN PEMBAHASAN}

Komunikasi rembug desa sebagai salah satu bentuk kearifan lokal yang menurut (Keraf, 2002) adalah semua bentuk pengetahuan, keyakinan dan etika yang menuntun prilaku masyarakat. Dalam masyarakat desa hutan komunikasi rembug desa bertujuan untuk menumbuhkan partisipasi masyarakat dalam mengelola hutan, komunikasi rembug desa polanya bersifat dialogis lebih banyak terjadi pada (Wiryono, 1998) pola komunikasi dibentuk untuk mengidentikasi dan mengkategorikan unsur-unsur yang relevan dari suatu proses komunikasi khususnya komunikasi interpersonal. Pola komunikasi adalah representasi dari suatu peristiwa komunikasi yang dapat digunakan untuk melihat unsurunsur yang terlibat dalam komunikasi. Sedangkan komunikasi yang efektif menurut ( Susanto 1989) tergantung bagaimana relevansi antara pola komunikasi yang dipakai dengan kondisi sosial, budaya dan psikologis khalayak. Komunikasi yang efektif jika terjadi dalam suasana yang menguntungkan, menggunakan bahasa yang mudah dimengerti dan pesannya menggugah perhatian dan minat komunikan. Severin dan Tankard dalam (Wiryanto, 1998) berpendapat pola komunikasi dapat membantu merumuskan suatu teori dan menyarankan suatu bentuk relasi. Pola komunikasi mempunyai tiga proses (1) menggambarkan proses komunikasi (2) menunjukkan hubungan visual (3) membantu menemukan dan memperbaiki 
hambatan komunikasi dan fungsinya dalam (Sendjaya , 1999) mempunyai empat fungsi yaitu pengorganisasian (2) penjelasan (3) heuristic, yang memberikan gambaran mengenai unsur-unsur pokok dari suatu proses atau sistem dan (4) prediksi akibat yang terjadi.

Beberapa pola komunikasi rembug desa sebagai bentuk kearifan lokal yang menurut Francis Wahono dalam (Suhartini, 2009) semua kepandaian, strategi pengelolaan alam dalam menjaga keseimbangan ekologis yang sudah lama teruji oleh berbagai bencana dan keteledoran manusia, dapat dijelaskan melalui teori komunikasi sebagai berikut :

1. Teori komunikasi Intrapribadi atau intrapersonal communication merupakan proses pengolahan dan penyusunan informasi melalui sistem syaraf karena adanya stimulus yang ditangkap oleh pancaindera, proses berpikir merupakan bagian dari komunikasi intrapribadi (Sendjaja , 1999).

2. Teori Komunikasi Antarpribadi atau interpersonal communication, merupakan proses selanjutnya dari komunikasi intrapribadi yang melibatkan unsur-unsur pesan berupa verbal maupun non verbal. Komunikasi antarpribadi terjadi dalam konteks pertemuan antara dua tiga orang atau lebih yang sifatnya spontan, tidak terstruktur, tidak mengejar tujuan yang direncanakan.

3. Teori stimulus Respons, adalah teori komunikasi yang paling sederhana dan mendasar yang menyatakan bahwa apabila ada aksi maka akan timbul reaksi yang asumsinya perilaku individu karena ada kekuatan stimulus bukan atas dasar motif atau sikap individu.

4. Teori Shannon dan Weaver, mengenalkan konsep mengenai redundancy dan entropy. Redundancy adalah pengulangan kata yang dapat menyebabkan rendahnya entropy. Informasi yang disampaikan memiliki tujuan untuk menambah pengetahuan, mengubah sikap dan perilaku individu. (Sendjaja,1999) 
Menurut Severin dan Tankard dalam (Wiryanto,1998) informasi adalah energi yang terpolakan yang mempengaruhi individu dalam mengambil keputusan dari kemungkinan pilihan-pilihan yang ada. Teori John Rilley dan Mathilda W. Rilly, dalam (Santosa, 2000) proses komunikasi menggunakan pendekatan sosiologi untuk mengkaji perilaku komunikasi antar manusia. Pesan yang disampaikan komunikator tidak langsung akan ditanggapi komunikan tetapi akan dipengaruhi oleh kelompok primer seperti keluarga inti atau kelompok rujukan yang ada dalam struktur sosial.

Secara kelembagaan komunikasi rembug desa terjadi dalam Forum Komunikasi Pengelolaan Hutan Bersama Masyarakat (FK PHBM) yang merupakan pendekatan kolaboratif atau silahturami yang berbasis pada masyarakat desa hutan dan melibatkan Perhutani, Stakeholder dan Pemerintahan setempat.

Dilihat dari $\begin{aligned} & \text { proses } \\ & \text { komunikasinya } \\ & \text { terjadi dalam }\end{aligned}$
komunikasi interpersonal dan
komunikasi kelompok yang polanya
bersifat dialogis atau interaktif, saling

mempengaruhi sebagai awal ikatan psikologis antara masyarakat desa hutan dengan Perhutani. Ikatan psikologis ini merupakan proses sosial untuk mengembangkan hutan lestari dengan berbagi peran dan tanggungjawab. Sebagai proses sosial dipengaruhi oleh proses komunikasi dan faktor sosial budaya.

Dalam komunikasi rembug desa dapat menumbuhkan harapan yang berorientasi masa kini dan mendatang maka dalam forum komunikasi rembug desa harapan tersebut diwujudkan dalam hutan yang lestari dan hutan yang lestari itu tersebut dapat terwujud bila masyarakat desa hutan tumbuh kesadaran akan pentingnya menjaga keamanan hutan. Kesadaran menjaga hutan itu diwujudkan dengan tidak merencek atau merambah hutan, sehingga fungsi ekologi dan ekonomi hutan bagi masyarakat desa hutan terus dapat terjamin.

Efektivitas forum komunikasi rembug desa terletak pada sifat komunikasi yang dialogis, umpan balik dan komunikatornya tokoh masyarakat desa hutan yang berfungsi sebagai change agent. Pengaruh change agent cukup besar dalam 
mengendalikan perilaku masyarakat desa hutan yang kemudian menjadi perilaku yang ajeg akan pentingnya keberlanjutan hutan yang berpengaruh pada meningkatnya kesejahteraan masyarakat desa hutan melalui sharing hasil hutan seperti jati, pinus, akasia dan getah kayu.

Dalam forum komunikasi rembug desa hutan yang dilaksanakan secara berkala disampaikan informasi yang berupa (1) informational message seperti pemberitahuan tentang masalah hutan (2), instruksional message seperti perintah untuk menanam tanaman dibawah tegakan dengan sistem tumpang sari dan (3) motivational message seperti meningkatkan kesadaran akan kelestarian hutan.

Masyarakat desa hutan rata-rata berpendidikan rendah maka dalam rembug desa sharing informasi dilakukan secara apa adanya, tanpa basa-basi, humor malah kadang seronok yang seolah-olah tidak ada etikanya.

Proses komunikasi rembug desa akan terjadi (1) perilaku spontan, terjadi secara tiba-tiba, serta merta tanpa berpikir mendalam dulu yang sering menimbulkan gelak tawa perilaku scripted karena dorongan faktor kebiasaan seperti nampak dalam logat atau dialek ngapak-apak sebagai dialek Banyumasan perilaku contrived, dipengaruhi motif kognitif dan sikap rasionalitasnya seperti tidak asal bunyi.

Dalam forum komunikasi rembug desa hutan mereka berbagi perasaan, saling berempati karena mereka merasa saling tergantung. Mereka membuat aturan yang mengikat masyarakat desa hutan dan aturan itu mempengaruhi sikap konformitas diantara masyarakat desa hutan seperti ketika menanam tanaman yang sama dibawah tegakan seperti tumpangsari.

Sebagai forum kolaborasi komunikasi rembug desa dapat memberi keuntungan antara lain (1) sebagai sharing informasi antara masyarakat desa hutan, KPH dan stakeholder (2) mengambil keputusan efektif yang fokusnya pada masalah bersama mengembangkan kapasitas kelembagaan.

Undang-Undang Dasar 1945 mengamanatkan bahwa bumi dan air dan kekayaan alam yang terkandung didalamnya dikuasai negara dan 
digunakan untuk sebesar-besarnya kemakmuran rakyat. Sebagaimana diamanatkan konstitusi tersebut maka hutan sebagai bagian dari bumi dikuasai negara untuk sebesarsebesarnya kemakmuran rakyat.

Hutan sebagai salah satu modal pembanguan nasional mempunyai manfaat yang nyata bagi kehidupan rakyat Indonesia baik manfaat ekonomi, ekologi dan sosial budaya . Oleh karena itu harus dikelola dan dimanfaatkan secara berkesinambungan baik untuk generasi sekarang maupun yang akan datang.

\section{Undang-Undang Nomor 41} tahun 1999 tentang Kehutanan ditetapkan bahwa hutan sebagai salah satu penyangga kehidupan dan sumber kemakmuran rakyat maka hutan harus dijaga daya dukungnya secara keberlanjutan, diurus dengan akhlak mulia, asas kerakyatan, asas keadilan, asas kebersamaan, asas keterbukaan, asas keterbukaan dan asas keterpaduan.

Status dan fungsi hutan diatur dalam pasal 5 sampai dengan 9 Undang - Undang Kehutanan Nomor 41 tahun 1999., tentang status hutan diatur dalam pasal 5 bahwa status hutan terdiri hutan negara dan hutan hak, sedangkan fungsi hutan diatur dalam pasal 6 ayat 1 yang menyatakan hutan mempunyai fungsi konservasi, fungsi lindung dan fungsi produksi.

Pengelolaan Hutan lestari menurut Perum Perhutani adalah kegiatan pengelolaan sumberdaya hutan untuk mencapai satu atau lebih tujuan yang telah ditetapkan, yang berkaitan dengan produksi kayu dan non kayu . Pengelolaan sumberdaya hutan ini dilakukan dengan mengoptimalakan peran dan fungsi hutan secara lestari ekonomi, lingkungan dan sosial kemasyarakatan.

Pengembangan hutan lestari menurut (Perhutani, 2002) didasari karakteristik permasalahan hutan yang dihadapi dan pengalaman panjang dalam mengelola hutan yaitu:

1. Community Based Forest Managemen (CBFM), pengelolaan hutan melibatkan masyarakat sekitar hutan untuk berpartisipasi akatif mulai dari perencanaan, pengelolaan hingga pengawasan hutan dimana ketiga prinsip tersebut oleh Perum Perhutani 
KEARIFAN LOKAL LINGKUNGAN KOMUNIKASI REMBUG DESA DALAM MENJAGA

KELESTARIAN HUTAN DI KESATUAN PEMANGKUAN HUTAN (KPH) BANYUMAS TIMUR

dijabarkan dalam program pendekatan sebagai berikut : (1)

Pengelolaan Hutan Bersama prosperity approach, kesejahteraan

Masyarakat (PHBM) atau masyarakat desa hutan berkorelasi

secara umum dikenal sebagai positif terhadap keamanan

hutan sosial.

2. Resources Based Forest

Management, usaha Perhutani

tidak semata-mata

memproduksi kayu dan hasil

hutan lainnya tetapi juga

mengelola ekosistem dan

seluruh sumberdaya hutan yang

terkandung di dalam maupun di

permukaan seperti air, galian $\mathrm{C}$,

agrobisnis yang ditujukan bagi

kesejahteraan masyarakat .

3. Penerapan Good Corporate

Gavermance dalam seluruh

aspek pengelolaan hutan,

artinya bahwa seluruh aktivitas

pengelolaan hutan harus

memenuhi unsur asas

transparansi, fairness,

akuntabilitas, kemandirian,

kewajaran untuk perbaikan

manajemen yang dapat

menjamin kelestarian hutan.

Adapun strategi pengamanan

hutan lestari menurut (Perhutani,

2008) sebagai implementasi dari

kebijakan kehutanan tersebut diatas

dilakukan melalui beberapa

sumberdaya, makin meningkat

kesejahteraan masyarakat sekitar

hutan maka makin kecil terjadinya

kerusakan hutan (2) education

approach, makin tinggi tingkat

pendidikan masyarakat desa hutan

berkorelasi positif dengan tingkat

pemahaman akan fungsi dan manfaat

hutan dan kepada kepatuhan pada

hukum maupun peraturan

perundangan lainnya tentang sumber

daya hutan. Penyuluhan tentang sumberdaya hutan dilakukan melalui rembug desa yang sering dilakukan masyarakat desa hutan

participation approach, dilakukan untuk meningkatkan rasa memiliki masyarakat desa hutan terhadap sumber daya hutan. Makin besar rasa memiliki makin besar semangatnya untuk menjaga dan melestarikan hutan, pendektan ini dilakukan melalui forum komunikasi rembug desa, (4) local wisdom masyarakat desa hutan, yang diwariskan secara turun temurun sudah mempunyai kepedulian yang tinggi dalam melestarikan hutan hal ini nampak 
KEARIFAN LOKAL LINGKUNGAN KOMUNIKASI REMBUG DESA DALAM MENJAGA

KELESTARIAN HUTAN DI KESATUAN PEMANGKUAN HUTAN (KPH) BANYUMAS TIMUR

pada pola bercocok tanam yang memperhatikan konservasi.

Pelestarian kearifan lokal dilakukan dengan menghormati hak ulayat dan hak adat lainnya dan melindungi situs budaya lokal.

\section{KESIMPULAN}

1. Kearifan lokal komunikasi rembug desa yang merupakan lembaga demokrasi masyarakat desa hutan sebagai ajang bicara spontan, terus terang, tanpa basa-basi dan sebagai forum pengambilan keputusan secara musyawarah dan mufakat tanpa ada merasa yang terpinggirkan, dapat menumbuhkan kesadaran dan partisipasi masyarakat desa hutan akan pentingnya menjaga kelestarian sumber daya hutan dengan tidak melakukan perambahan hutan atau perencekan tegakkan hutan.

2. Hutan yang lestari ditandai dengan adanya struktur hutan yang tidak lagi hanya dikelola oleh negara tetapi juga melibatkan masyarakat desa hutan atau lebih dikenal dengan social forestry yang oleh Perhutani di adopsi menjadi 
Keraf, Sony. 2006. Etika Dokumen - Dokumen

Lingkungan.Jakarta: Kompas.

Santosa. 2000. Komunikasi

Pembangunan. Bandung:

Alumni.

Sendjaya S. 1999. Pengantar Ilmu

Komunikasi.Jakarta: Universitas

Terbuka.

Soemarwoto, Otto. 1991. Ekologi Lingkungan Hidup dan

Pembangunan.Jakarta: Penerbit

Djambatan.

Soerjani. 1997. Pembangunan dan

Lingkungan Meniti Gagasan dan

Pelaksanaan Sustainable

Development. Jakarta: Institut

Pendidikan dan Pengembangan

Lingkungan.

Stevens, B. 2001. Community Forestry Solusi Nyata, Journal Community Forestry VOL 4 .

Suhartini. 2009. Prosiding Seminar Nasional Penelitian, Pendidikan dan Penerapan, Fakultas MIPA, Universitas Negeri Jogyakarta.

Susanto, Astrid. 1989. Komunikasi

Kontemporer. Bandung:

Binacipta.
1. Undang-Undang No 23 tahun $1997 \quad$ Tentang Pengelolaan Lingkungan Hidup

2. Undang-Undang No 41 tahun $1999 \quad$ Tentang Kehutanan

3. Undang-Undang No 32 tahun 2004, Tentang Otonomi Daerah .

4. .Perhutani Unit ! Jawa Tengah, 2002, Petunjuk Pelaksanaan Pengelolaan Sumberdaya Hutan Bersama Masyarakat di Unit I Jawa Tengah . 